J. Clin. Chem. Clin. Biochem.

Vol. 16,1978 , pp. $165-173$

\title{
Oligoclonal Immunoglobulins, Light Chain Ratios and Free Light Chains in Cerebrospinal Fluid and Serum from Patients Affected with Various Neurological Diseases
}

\author{
By F. Bollengier, N. Rabinovitch and A. Lowenthal \\ Laboratorium Fysiopathologie van het Zenuwstelsel, Vrije Universiteit Brussel, Brussels, Belgium
}

(Received May 6, 1977)

Summary: Several immunological parameters, of which the most important are the kappa-lambda ratios, the presence of free light chains and the double ring formation for kappa-chains in single radial immunodiffusion, were investigated in the cerebrospinal fluid and serum of patients affected with different neurological diseases. Parallels were run either with multiple sclerosis or subacute sclerosing panencephalitis. There seems to be a correlation between the frequency of the presence of free light chains and the degree of severity of the immunological process.

\section{Oligoklonale Immunoglobuline, Leicht-Ketten-Verhältnisse und freie leichte Ketten in Liquor und Serum von Patienten mit verschiedenen neurologischen Erkrankungen}

Zusammenfassung: Mehrere immunologische Parameter, von denen die $\kappa / \lambda$-Verhältnisse, das Vorkommen freier leichter Ketten und die Doppel-Ring-Bildung für $\kappa$-Ketten in der einfachen radialen Immundiffusion am wichtigsten sind, wurden in Liquor und Serum von Patienten mit verschiedenen neurologischen Erkrankungen untersucht. Parallele Untersuchungen wurden angelegt entweder mit multipler Sklerose oder mit subakuter sklerosierender Panencephalitis. Hier scheint es keine Korrelation zwischen der Häufigkeit des Vorkommens freier leichter Ketten und dem Schweregrad des immunologischen Prozesses zu geben.

\section{Introduction}

In a previous paper (1) we investigated the kappalambda light chain ratios, the presence of free light chains and the double ring formation in single radial immunodiffusion in the serum and cerebrospinal fluid of patients affected with subacute sclerosing panencephalitis; several cases of multiple sclerosis were also considered at the same time.

In a recent paper (2), eleven different biochemical and immunological parameters, including bound and free kappa-lambda light chain distribution and the pattern from thin layer isofocusing were studied in the cerebrospinal fluid of 36 multiple sclerensis patients.

We came to the conclusion that on the one hand, synthesis of particular immunoglobulins, carrying light chains with incomplete antigenic determinants could be possible both in subacute sclerosing panencephalitis and multiple sclerosis; and on the other hand, synthesis of free light chains could be due to a strong immunological stimulation, since hyperimmunisation is a well established feature of subacute sclerosing panencephalitis. In multiple sclerosis, the viral etiology has never been clearly and definitely established, but it is nevertheless a well known fact that there are important immunological impairments in this disease.

In the present paper we investigate a series of parameters of which the most important are the kappalambda ratios, the presence of free light chains and the double precipitation ring phenomenon (3), in the cerebrospinal fluid and serum of patients grouped according to 6 different neurological diseases. For comparison, earlier determinations performed on material from patients with subacute sclerosing panencephalitis and multiple sclerosis were reinvestigated.

The purpose was to determine whether the presence of free light chains could be considered as an index of hy perimmunisation, or at least as an index of a prolonged and strong immunological process; simultaneously we looked for the presence of partic- 
ular immunoglobulins in neurological diseases other than subacute sclerosing panencephalitis and multiple sclerosis.

\section{Material and Methods}

We considered the following neurological diseases:

1. amyotrophic lateral sclerosis

2. cervical myelopathy

3. polyneuropathy including polyneuritis and Guillain-Barré syndrome

4. 3 types of inflammatory diseases:
a) meningitis
b) viral and parasitic encephalitis
c) neurosyphilis

Diagnosis was based on the clinical course of the diseases, on the electro-encephalogram, thorough routine examination of the serum and cerebrospinal fluid (total proteins, cell counting, etc), agar gel electrophoresis, and when necessary, on titration of the viral antibodies.

Cerebrospinal fluid was collected by lumbar puncture and used immediately or kept frozen at $-20^{\circ} \mathrm{C}$. The samples were utilized concentrated or unconcentrated depending on the different techniques used. Agar gel electrophoresis was carried out according to Wieme (4). The bound and free light chain determinations were performed as described previously (1) and the IgG content was determined by single radial immunodiffusion (5) using LC Partigen plates (LC Partigen - IgG - TCR/03 - Behringwerke AG - Marburg/Lahn.)

Control cerebrospinal fluid was obtained from patients either without or with minor neurological syndromes. These samples were considered normal by routine as well as by electrophoretic examinations.

Control serum was taken from healthy donors.

\section{Results}

Table 1 groups the results from 5 cases of amytrophic lateral sclerosis and 3 cases of supposed cervical myelopathy.
In cases of amyotrophic lateral sclerosis, the IgG values were within the range of controls, and the $\left.k / \lambda^{1}\right)$ values were slightly different from the controls (tab. 1 and 4).

In cervical myelopathy (diagnozed on the basis only of clinical and radiological examinations) the IgG were increased and the $k / \lambda$ was disturbed (tab. 1 and 4). Moreover free light chains were detected, the double ring precipitation was present, and all 3 cases showed fractionated IgG in agar gel electrophoresis. These findings lead us to the conclusion that these 3 cases were in fact missdiagnnozed cases of multiple sclerosis.

In table 2 the same parameters are shown for the polyneuropathy and meningitis group.

One polyneuritis case had increased IgG, and 2 cases had increased $\kappa / \lambda$ values. All the Guillain-Barre displayed considerably increased IgG, and 5 of them showed disturbed $\kappa / \lambda$ values. For the whole group predominantly free light chains were detected, and double ring precipitation and fractionated IgG were also occasionally present (tab. 2). Meningitis cerebrospinal fluid displayed slightly increased IgG values; however cases 10 and 11 , which were patients affected with tuberculous meningitis, showed a considerable increase.

7 out of the 11 cases had $\kappa / \lambda$ values lower than control values; both $\kappa$ and $\lambda$ free chains were present; double ring precipitation was noticed in 5 cases, but fractionated IgG-globulins were seen in 7 of the 11 cases.

Table 3 groups 16 cases of viral and parasitic encephalitis and 6 cases of neurosyphilis. The responsible viral antigens were identified in 11 of the 15 cases of encephalitis. The major antigens were herpes, mumps and parainfluenza virus and filariasis.

1) $\kappa / \lambda=$ kappa-lambda light chain ratio.

Tab. 1. Immunological parameters in cerebrospinal fluid from patients affected with amyotrophic lateral sclerosis and cervical myelopathy.

\begin{tabular}{|c|c|c|c|c|c|c|}
\hline & $\begin{array}{l}\mathrm{IgG} \\
\mathrm{mg} / 1\end{array}$ & $\begin{array}{l}\kappa / \lambda \\
\text { ratio }\end{array}$ & $\begin{array}{l}\text { Free } \\
\kappa \text {-chain } s^{a}\end{array}$ & $\begin{array}{l}\text { Free } \\
\lambda \text {-chains }\end{array}$ & $\begin{array}{l}\text { Double ring } \\
\text { precipitation } b\end{array}$ & $\begin{array}{l}\text { Agar gel } \\
\text { electröphoresisc }\end{array}$ \\
\hline Patients $n=5$ & & & \multicolumn{4}{|c|}{ Amyotrophic lateral sclerosis } \\
\hline $\begin{array}{l}1 \\
2 \\
3 \\
4 \\
5\end{array}$ & $\begin{array}{l}13.0 \\
11.0 \\
18.0 \\
30.0 \\
14.0\end{array}$ & $\begin{array}{l}2.5 \\
3.7 \\
1.7 \\
2.4 \\
2.7\end{array}$ & $\begin{array}{l}- \\
- \\
- \\
-\end{array}$ & $\begin{array}{l}- \\
= \\
- \\
-\end{array}$ & $\begin{array}{l}- \\
- \\
- \\
-\end{array}$ & $\begin{array}{l}- \\
- \\
- \\
-\end{array}$ \\
\hline Patients $n=3$ & & & \multicolumn{4}{|c|}{ Cervical myelopathy } \\
\hline $\begin{array}{l}1 \\
2 \\
3\end{array}$ & $\begin{array}{l}57.0 \\
26.0 \\
80.0\end{array}$ & $\begin{array}{l}4.2 \\
3.0 \\
1.7\end{array}$ & $\begin{array}{l}+ \\
+ \\
-\end{array}$ & - & $\begin{array}{l}+ \\
+ \\
-\end{array}$ & $\begin{array}{l}+ \\
+ \\
+\end{array}$ \\
\hline
\end{tabular}

$a=+$ free chains present, - negative

$\mathrm{b}=+$ double ring precipitation present, - absent

$c=+$ fractionation obvious; \pm fractionation doubtful; - no fractionation 
Tab. 2. Immunological parameters in cerebrospinal fluid from patients affected with polyneuropathy and meningitis.

\begin{tabular}{|c|c|c|c|c|c|c|}
\hline & $\begin{array}{l}\mathrm{IgG} \\
\mathrm{mg} / 1\end{array}$ & $\begin{array}{l}\kappa / \lambda \\
\text { ratio }\end{array}$ & $\begin{array}{l}\text { Free } \\
\kappa \text {-chains }\end{array}$ & $\begin{array}{l}\text { Free } \\
\lambda \text {-chains }\end{array}$ & $\begin{array}{l}\text { Double ring } \\
\text { precipitation } b\end{array}$ & $\begin{array}{l}\text { Agar gel } \\
\text { electrophoresisc }\end{array}$ \\
\hline Patients $n=12$ & & & Polyneuro & thy & & \\
\hline $\begin{array}{l}1 \\
2 \\
3 \\
4 \\
5 \\
6 \mathrm{~GB} \times \\
7 \mathrm{~GB} \\
8 \mathrm{~GB} \\
9 \mathrm{~GB} \\
10 \mathrm{~GB} \\
11 \mathrm{~GB} \\
12 \mathrm{~GB}\end{array}$ & $\begin{array}{r}22.0 \\
137.0 \\
- \\
21.0 \\
10.0 \\
90.0 \\
109.0 \\
33.0 \\
131.0 \\
68.0 \\
69.0 \\
220.0\end{array}$ & $\begin{array}{l}3.2 \\
1.8 \\
2.2 \\
1.8 \\
3.0 \\
3.1 \\
2.0 \\
2.8 \\
1.4 \\
1.4 \\
1.6 \\
2.2\end{array}$ & $\begin{array}{l}- \\
- \\
- \\
+ \\
\text { not eval. } \\
\overline{+} \\
\overline{-} \\
+ \\
- \\
- \\
\text { not eval. }\end{array}$ & $\begin{array}{l}- \\
+ \\
+ \\
+ \\
- \\
+ \\
+ \\
- \\
+ \\
+ \\
+ \\
+\end{array}$ & $\begin{array}{l}- \\
\overline{-} \\
- \\
\overline{+} \\
\overline{+} \\
\overline{-} \\
\overline{+}\end{array}$ & $\begin{array}{l}- \\
\pm \\
- \\
- \\
- \\
- \\
+ \\
+ \\
- \\
- \\
+ \\
\pm\end{array}$ \\
\hline Patients $n=11$ & & & Meningitis & & & \\
\hline $\begin{array}{c}1 \\
2 \\
3 \\
4 \\
5 \\
6 \\
7 \\
8 \\
9 \\
10 \mathrm{TM}^{*} \\
11 \mathrm{TM}^{\circ}\end{array}$ & $\begin{array}{r}- \\
38.0 \\
22.0 \\
13.0 \\
55.0 \\
50.0 \\
50.0 \\
30.0 \\
31.0 \\
200.0 \\
137.0\end{array}$ & $\begin{array}{l}2.7 \\
2.3 \\
3.3 \\
1.5 \\
1.6 \\
2.5 \\
1.8 \\
1.3 \\
0.9 \\
1.3 \\
1.6\end{array}$ & $\begin{array}{l}+ \\
- \\
+ \\
- \\
+ \\
- \\
+ \\
+ \\
+ \\
+\end{array}$ & $\begin{array}{l}+ \\
+ \\
+ \\
- \\
+ \\
- \\
+ \\
+ \\
+ \\
+ \\
+\end{array}$ & $\begin{array}{l}+ \\
- \\
+ \\
- \\
- \\
\bar{\kappa}, \lambda^{\circ} \\
- \\
+ \\
+ \\
-\end{array}$ & $\begin{array}{l}+ \\
\pm \\
- \\
- \\
+ \\
+ \\
- \\
+ \\
+ \\
+ \\
+\end{array}$ \\
\hline
\end{tabular}

$a=+$ free chains present, - negative

$\mathrm{b}=+$ double ring precipitation present, - absent

$c=+$ fractionation obvious; \pm fractionation doubtful, - no fractionation.

$x=$ Guillain-Barré syndrome

$0=$ double ring precipitation both for kappa and lambda chains

$*=$ Tuber culous meningitis

Notwithstanding a few exceptions, IgG values were increased, sometimes up to values as high as $660 \mathrm{mg} / \mathrm{l}$. In contrast, the $\kappa / \lambda$ ratios were mostly within the range of controls. However the presence of free light chains was highly positive and oligoclonal IgG appeared in 14 cases; the double ring precipitation phenomenon was observed in 8 cases.

The neurosyphilis group included 3 patients affected with active neurosyphilis (patient 1-2-3), 2 with asymptomatic neurosyphilis (patient 4-5) and 1 with congenital syphilis (patient 6).

In clinically active neurosyphilis IgG was increased and oligoclonal, the $\kappa / \lambda$ ratio was disturbed, and the free light chains and the double ring precipitations were observed in every case.

In contrast, in asymptomatic cases, the IgG was only slightly elevated and the $\kappa / \lambda$ ratio was almost within the range of the controls. No double ring precipitation was detected, but one case appeared fractionated in agar gel electrophoresis.

Table 4 gives the mean values $\pm \sigma$ and the significant differences between controls and pathological cases, and between subacute sclerosing panencephalitis and the remaining diseases (i. e. multiple sclerosis, amyotrophic lateral sclerosis, polyneuropathy, meningitis, viral encephalitis and syphilis).

It also summarizes the frequency of appearance of free light chains, the double ring precipitation phenomenon and oligoclonal IgG. For the mean IgG values, all the pathological cases, with the exception of amyotrophic lateral sclerosis, differed significantly from the controls. When the mean $k / \lambda$ values were considered, only amyotrophic lateral sclerosis, cervical myelopathy, multiple sclerosis and the neurosyphilis group differed significantly from controls.

When the group of infectious disorders was compared with subacute sclerosing panencephalitis, significant differences were observed between the IgG values of subacute sclerosing panencephalitis and syphilis. No significant differences were apparent in the $k / \lambda$ values for subacute sclerosing panencephalitis and the group of infectious disorders.

In multiple sclerosis, in which the principal characteristic is demyelination, the IgG values (but not the $\kappa / \lambda$ values) differ significantly from those found in subacute sclerosing panencephalitis. 
Tab. 3. Immunological parameters in cerebrospinal fluid from patients affected with viral and parasitic encephalitis and neurosyphilis.

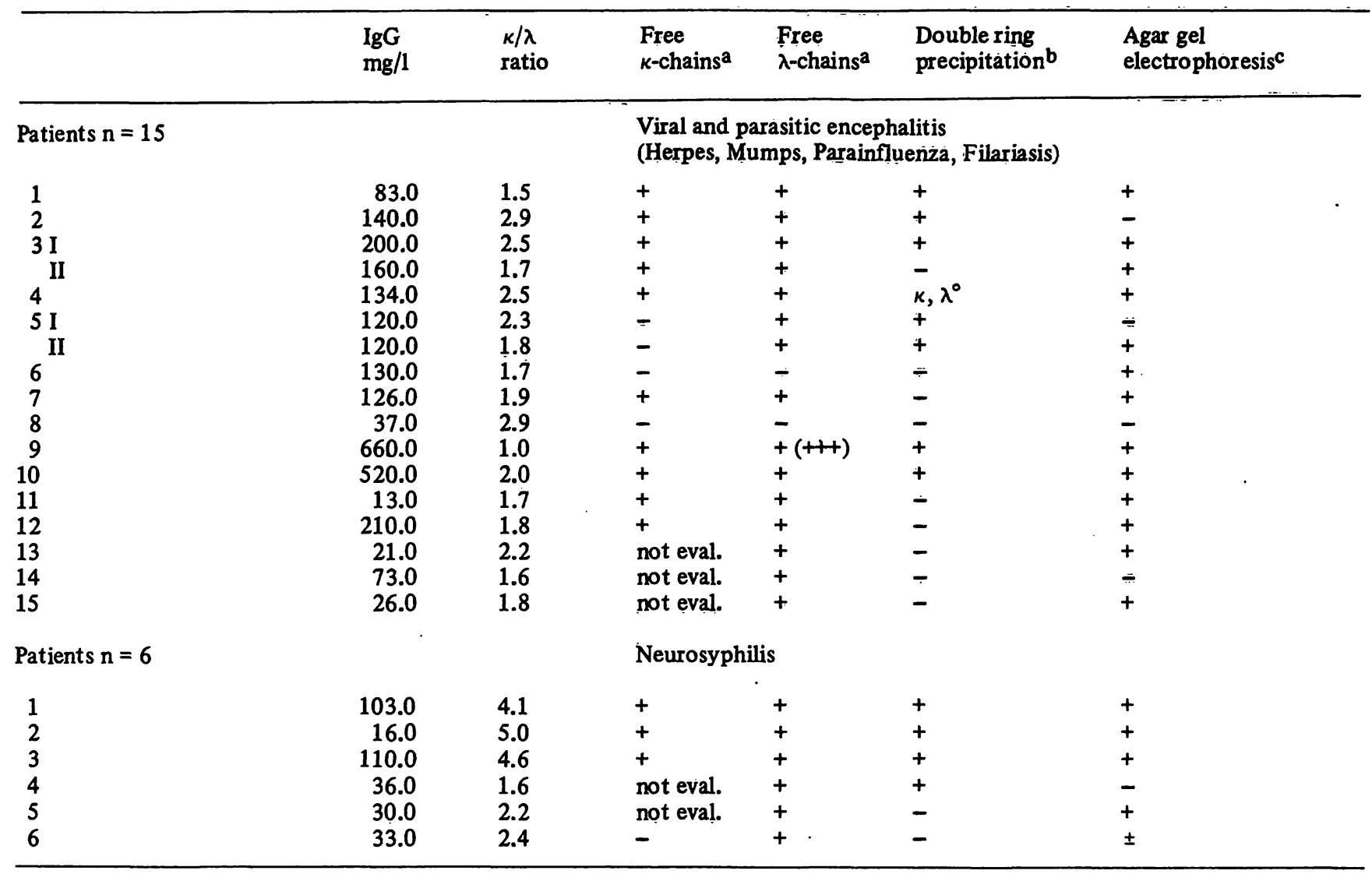

$\mathrm{a}=+$ free chains present, - negative

$\mathrm{b}=+$ double ring precipitation present, - absent

$c=+$ fractionation obvious: \pm fractionation doubtful; - no fractionation

$\mathrm{I}-\mathrm{II}=$ samples taken at 2 month interval

$o=$ double ring precipitation both for kappa and lambda light chains

Tab. 4. Mean values $\pm \sigma$ and the significant differences between control and pathological cerebrospinal fluid, and between subacute sclerosing panencephalitis and the remaining diseases for $0.005 \leqslant p \leqslant 0.01$.

\begin{tabular}{|c|c|c|c|c|c|c|}
\hline & $\begin{array}{l}\mathrm{IgG} \\
\mathrm{mg} / 1 \\
\bar{x} \pm \sigma\end{array}$ & $\begin{array}{l}\kappa / \lambda \\
\text { ratio } \\
\bar{x} \pm \sigma\end{array}$ & $\begin{array}{l}\text { Free } \\
\text {-chain } \\
\% \text { fre- } \\
\text { quency }\end{array}$ & $\begin{array}{l}\text { Free } \\
\text {-chain } \\
\text { \% fre- } \\
\text { quency }\end{array}$ & $\begin{array}{l}\text { Double ring } \\
\text { precipitation }\end{array}$ & $\begin{array}{l}\text { Agar gel } \\
\text { electrophoresis } \\
\text { \% fractionation }\end{array}$ \\
\hline $\begin{array}{l}\text { Controls } \\
\quad n=24\end{array}$ & $18.5 \pm 7.4$ & $2.06 \pm 0.35$ & 0 & 0 & 0 & 0 \\
\hline $\begin{array}{l}\text { Amyotrophic lateral } \\
\text { sclero sis } \\
\quad n=5\end{array}$ & $17.2 \pm 7.6$ & $2.60 \pm 0.72^{+}$ & 0 & 0 & 0 & 0 \\
\hline $\begin{array}{l}\text { Cervical myelopathy } \\
\qquad n=3\end{array}$ & $54.3 \pm 27.1 *$ & $2.97 \pm 1.85^{*}$ & 66 & 33 & 66 & 100 \\
\hline $\begin{array}{l}\text { Multiple sclerosis } \\
\quad n=48\end{array}$ & $71.8 \pm 54.0 * \Delta$ & $3.37 \pm 2.76^{*}$ & 80 & 65 & 98 & 77 \\
\hline $\begin{array}{l}\text { Polyneuropathy } \\
\qquad n=12\end{array}$ & $82.7 \pm 63.7 *$ & $2.21 \pm 0.66$ & 30 & 75 & 33 & 25 \\
\hline $\begin{array}{c}\text { Meningitis } \\
\mathrm{n}=11\end{array}$ & $62.6 \pm 59.2 * \Delta$ & $1.89 \pm 0.72$ & 64 & 82 & 45 & 64 \\
\hline $\begin{array}{l}\text { Viral \& parasitic } \\
\text { encephalitis } \\
\quad n=15\end{array}$ & $172.3 \pm 173.9 *$ & $2.24 \pm 0.52$ & 60 & 87 & 47 & 73 \\
\hline $\begin{array}{l}\text { Neuro'syphilis } \\
n=6\end{array}$ & $59.5 \pm 40.8 * \Delta$ & $3.32 \pm 1.42^{*}$ & 75 & 100 & 50 & 66 \\
\hline $\begin{array}{l}\text { Subacute sclerosing } \\
\text { panencephalitis } \\
n=14\end{array}$ & $116.6 \pm 38.8 * 0 \Delta$ & $2.56 \pm 1.74$ & 100 & 100 & 92 & 100 \\
\hline
\end{tabular}

$*$ = pathological values differ from controls for $p<0.005$

$+=$ amyotro phic lateral sclerosis values differ from controls for $0.005<p<0.01$

$o=$ meningitis values differ from subacute sclerosing panencephalitis for $0.005<p \leqslant 0.01$

$\Delta=$ neurosyphilis and multiple sclerosis values differ from subacute sclerosing panencephalitis for $p \leqslant 0.005$ 
The highest frequencies of free light chains, of double ring precipitation and fractionation in the IgG were found in subacute sclerosing panencephalitis, and in multiple sclerosis.

Tables 5 and 6 show IgG values, $k / \lambda$ ratios, the presence or absence of double ring precipitation and the agar gel electrophoresis pattern for several groups of pathological sera.

The free light chains were not reported, as their quantitative presence did not exceed the values of free light chains in control sera (6): there were a few exceptions, however, in subacute sclerosing panencephalitis (unpublished results).

In amyotrophic lateral sclerosis, sera IgG values were entirely normal, and the $\kappa / \lambda$ values were lower than the controls (tab. 5 and 7), no double ring precipitation or oligoclonal IgG were detected.

In multiple sclerosis, IgG values were fairly normal, but the $\kappa / \lambda$ ratios were widely spread, ranging from 1.8 to 4.0. No double ring precipitation or fractionated IgG were observed.

Polyneuropathy cases also had IgG values within the control range and the $\kappa / \lambda$ values varied between 1.1 and 2.0. No double ring precipitation was present,

Tab. 5. Immunological parameters in serum from patients affected with amyotrophic lateral sclerosis and multiple sclerosis.

\begin{tabular}{|c|c|c|c|c|}
\hline & $\begin{array}{l}\text { IgG } \\
\mathrm{g} / 1\end{array}$ & $\begin{array}{l}\kappa / \lambda \\
\text { ratio }\end{array}$ & $\begin{array}{l}\text { Double ring } \\
\text { precipitation* }\end{array}$ & $\begin{array}{l}\text { Agar gel } \\
\text { electrophoresis }\end{array}$ \\
\hline $\begin{array}{l}\text { Patients } \\
n=4\end{array}$ & & \multicolumn{3}{|c|}{ Amyotrophic lateral sclerosis } \\
\hline $\begin{array}{l}1 \\
2 \\
3 \\
4\end{array}$ & $\begin{array}{l}12.7 \\
10.2 \\
10.2 \\
14.4\end{array}$ & $\begin{array}{l}1.9 \\
1.4 \\
1.5 \\
1.5\end{array}$ & $\begin{array}{l}- \\
- \\
- \\
-\end{array}$ & $\begin{array}{l}- \\
- \\
-\end{array}$ \\
\hline $\begin{array}{l}\text { Patients } \\
n=16\end{array}$ & & \multicolumn{3}{|c|}{ Multiple sclerosis } \\
\hline $\begin{array}{r}1 \\
2 \\
3 \\
4 \\
5 \\
6 \\
7 \\
8 \\
9 \\
10 \\
11 \\
12 \\
13 \\
14 \\
15 \\
16\end{array}$ & $\begin{array}{r}7.5 \\
6.5 \\
12.2 \\
6.5 \\
14.6 \\
9.3 \\
110.5 \\
11.9 \\
14.4 \\
10.7 \\
12.9 \\
14.4 \\
14.0 \\
15.1 \\
10.1 \\
10.7\end{array}$ & $\begin{array}{l}3.3 \\
3.3 \\
2.8 \\
4.0 \\
3.7 \\
2.4 \\
1.9 \\
3.1 \\
2.9 \\
3.0 \\
3.8 \\
2.7 \\
2.8 \\
2.5 \\
2.0 \\
1.8\end{array}$ & $\begin{array}{l}\overline{-} \\
\bar{z} \\
\overline{-} \\
\overline{-} \\
\bar{z} \\
\overline{-} \\
\overline{-} \\
\overline{-} \\
\overline{-}\end{array}$ & $\begin{array}{l}- \\
- \\
- \\
= \\
- \\
- \\
= \\
- \\
= \\
- \\
- \\
- \\
- \\
- \\
=\end{array}$ \\
\hline
\end{tabular}

$*=+$ double ring percipitation present, - absent

$0=+$ fractionation obvious, \pm fractionation doubtful,

- no fractionation
Tab. 6. Immunological parameters in serum from patients affected with polyneuropathy, viral encephalitis and subacute sclerosing panencephalitis.

\begin{tabular}{|c|c|c|c|c|}
\hline & $\begin{array}{l}\text { IgG } \\
\text { g/1 }\end{array}$ & $\begin{array}{l}\kappa / \lambda \\
\text { ratio }\end{array}$ & $\begin{array}{l}\text { Double ring } \\
\text { precipitation* }\end{array}$ & $\begin{array}{l}\text { Agar gel } \\
\text { electrophoresis }\end{array}$ \\
\hline $\begin{array}{l}\text { Patients } \\
\mathrm{n}=4\end{array}$ & & & \multicolumn{2}{|l|}{ Polyneuropathy } \\
\hline $\begin{array}{l}1 \mathrm{~GB}^{+} \\
2 \mathrm{~GB} \\
3 \\
4\end{array}$ & $\begin{array}{r}6.1 \\
11.0 \\
12.3 \\
10.8\end{array}$ & $\begin{array}{l}1.5 \\
1.1 \\
1.9 \\
2.0\end{array}$ & $\begin{array}{l}- \\
\overline{-} \\
-\end{array}$ & $\begin{array}{l}+ \\
- \\
-\end{array}$ \\
\hline $\begin{array}{l}\text { Patients } \\
\mathrm{n}=11\end{array}$ & & & \multicolumn{2}{|c|}{ Viral encephalitis } \\
\hline $\begin{array}{c}1 \mathrm{a} \\
\mathrm{b} \\
2 \\
3 \\
4 a \\
\mathrm{~b} \\
5 \mathrm{a} \\
\mathrm{b} \\
6 \\
7 \\
8 \\
9 \\
10 \\
11\end{array}$ & $\begin{array}{r}7.4 \\
7.8 \\
13.8 \\
10.0 \\
9.1 \\
8.2 \\
4.4 \\
8.0 \\
4.7 \\
23.8 \\
17.2 \\
21.2 \\
9.5 \\
14.0\end{array}$ & $\begin{array}{l}1.6 \\
1.4 \\
1.3 \\
1.6 \\
2.2 \\
1.7 \\
2.0 \\
1.9 \\
2.0 \\
1.1 \\
2.5 \\
1.6 \\
1.7 \\
1.3\end{array}$ & $\begin{array}{l}- \\
\overline{-} \\
\overline{-} \\
\overline{-} \\
\overline{-} \\
\overline{-} \\
\overline{-} \\
\overline{-} \\
-\end{array}$ & $\begin{array}{l}- \\
- \\
+ \\
+ \\
- \\
- \\
- \\
\overline{+} \\
\pm \\
- \\
- \\
-\end{array}$ \\
\hline $\begin{array}{l}\text { Patients } \\
\mathrm{n}=14\end{array}$ & & & \multicolumn{2}{|c|}{$\begin{array}{l}\text { Subacute sclerosing } \\
\text { panencephalitis }\end{array}$} \\
\hline $\begin{array}{r}1 \\
2 \\
3 \\
4 \\
5 \\
6 \\
7 \\
8 \\
9 \\
10 \\
11 \\
12 \\
13 \\
14\end{array}$ & $\begin{array}{l}16.4 \\
13.3 \\
10.0 \\
15.5 \\
16.2 \\
14.3 \\
19.1 \\
12.2 \\
13.5 \\
17.3 \\
19.4 \\
19.8 \\
14.2 \\
21.2\end{array}$ & $\begin{array}{l}3.8 \\
1.5 \\
2.1 \\
2.0 \\
1.5 \\
2.1 \\
2.4 \\
2.1 \\
2.1 \\
2.4 \\
2.5 \\
3.0 \\
2.2 \\
1.5\end{array}$ & $\begin{array}{l}- \\
- \\
- \\
- \\
- \\
- \\
- \\
- \\
- \\
- \\
- \\
- \\
-\end{array}$ & $\begin{array}{l}+ \\
+ \\
+ \\
+ \\
+ \\
+ \\
+ \\
+ \\
+ \\
+ \\
+ \\
+ \\
+ \\
+\end{array}$ \\
\hline
\end{tabular}

$*=+$ double ring precipitation present, - absent

$o=+$ fractionation obvious, \pm fractionation doubtful, - no fractionation

$+=$ GB: Guillain-Barré syndrome

a) -b) = samples taken at 2 month interval

but one serum from a patient affected with GuillainBarré syndrome was fractionated in agar gel electrophoresis.

The IgG values of viral encephalitis sera were widely spread between $4.40 \mathrm{~g} / 1$ and $23.80 \mathrm{~g} / 1$. The $\kappa / \lambda$ values were slightly decreased in comparison to mean control values. Double ring precipitation was absent, but 2 sera presented definite oligoclonal IgG and 2 others showed fractionation.

In subacute sclerosing panencephalitis IgG was increased and the $k / \lambda$ was within the range of the controls for 9 out of the 14 cases; no double ring precipitation 
Tab. 7. Mean values $\pm \sigma$ and the significant differences between control and pathological sera, and between subacute sclerosing panencephalitis and the remaining diseases for $0.005 \leqslant \mathrm{p} \leqslant 0.01$.

\begin{tabular}{|c|c|c|c|c|}
\hline & $\begin{array}{l}\text { IgG } \\
g / 1 \\
\bar{x} \pm \sigma\end{array}$ & $\begin{array}{l}\kappa / \lambda \\
\text { ratio } \\
\bar{x} \pm \sigma\end{array}$ & $\begin{array}{l}\text { Double ring } \\
\text { precipitation } \\
\% \text { frequency }\end{array}$ & $\begin{array}{l}\text { Agar gel } \\
\text { electrophoresis } \\
\% \text { fractionation }\end{array}$ \\
\hline Controls $n=20$ & $11.72 \pm 0.80$ & $2.31 \pm 0.23$ & 0 & 0 \\
\hline Amyotrophic lateral sclerosis $n=4$ & $11.88 \pm 2.06$ & $1.58 \pm 0.22 * \Delta$ & 0 & 0 \\
\hline Multiple sclerosis $n=16$ & $11.33 \pm 2.86^{\circ}$ & $2.88 \pm 0.66 * 0 \Delta$ & 0 & 0 \\
\hline Polyneuropathy $n=4$ & $10.05 \pm 2.73^{\circ}$ & $1.63 \pm 0.41^{*+}$ & 0 & 0 \\
\hline Viral encephalitis $n=11$ & $10.90 \pm 5.96^{\circ}$ & $1.72 \pm 0.38^{*+}$ & 0 & 17 \\
\hline $\begin{array}{l}\text { Subacute sclerosing panencephalitis } \\
n=14\end{array}$ & $15.82 \pm 3.22 * 0$ & $2.23 \pm 0.61^{\circ+}$ & 0 & 93 \\
\hline
\end{tabular}

* = pathological values differ significantly from controls for $p \leqslant 0.005$

$o=$ multiple sclerosis, polyneuropathy and viral encephalitis values differ significantly from subacute sclerosing panencephalitis values for $0.005<\mathrm{p} \leqslant 0.01$

$+=$ polyneuropathy and viral encephalitis values differ from subacute sclerosing panencephalitis values for $0.005<p \leqslant 0.01$

$\Delta=$ amyotrophic lateral sclerosis differ from multiple sclerosis for $p \leqslant 0.005$

appeared, but all the sera, except one, were fractionated in agar gel electrophoresis.

Table 7 gives the mean values $\pm \sigma$ and the significant differences between controls and pathological values, between subacute sclerosing panencephalitis and the remaining group of neurological disorders; and finally between multiple sclerosis and amyotrophic lateral sclerosis.

It also represents the frequency of appearance of the double ring precipitation phenomenon and of IgG fractionation in agar gel electrophoresis. With respect to the IgG values, only subacute sclerosing panencephalitis differs significantly from controls, and from multiple sclerosis, polyneuropathy and viral encephalitis.

The frequency of the double ring precipitation phenomenon was zero for all cases under investigation; fractionation of the IgG-globulins reached $93 \%$ in subacute sclerosing panencephalitis, $17 \%$ in viral encephalitis, but was absent elsewhere.

\section{Discussion}

A general increase of IgG in the cerebrospinal fluid in multiple sclerosis and subacute sclerosing panencephalitis has been reported frequently in the literature.

When considering infectious disorders of the meninges as well as of the central nervous system, and neurological syndromes such as Guillain-Barre syndrome, this trend seems to be confirmed. The values we obtained were within the range of $10-660 \mathrm{mg} / \mathrm{l}$ which is in fairly good agreement with earlier findings (7).

From table 4 it becomes evident that the 4 different infectious disorders we observed, displayed IgG values which were significantly different from controls.
However, the highest values were recorded in subacute sclerosing panencephalitis, where hyperimmunisation against measles and/or measles-like virus had been clearly established $(8,9)$, and in severe cases of viral encephalitis, where hyperimmunisation against different viral antigens could be strongly suspected. There were indeed no significant differences between subacute sclerosing panencephalitis and viral encephalitis.

In fact, ranges as high as 660 and $520 \mathrm{mg} / 1$ (tab. 3) were seen in 2 cases of necrotizing herpetic encephalitis, where strong involvement with herpes virus had been proven by viral titration in the cerebrospinal fluid and brain biopsies.

Similar patterns have been observed by other authors $(10,11,12)$. In cases of neurosyphilis (tab. 3$)$ and tuberculous meningitis (tab. 2), where one could also suppose hyperimmunisation or at least strong immunisation against definite antigens (i. e. treponema pallidum and mycobacterium tuberculosis), IgG were fractionated and their values were prominent within their respective groups, and they approached the values for subacute sclerosing panencephalitis. Nevertheless, taken as a whole, syphilis and meningitis values were significantly different from subacute sclerosing panencephalitis cases.

In the polyneuropathy group, all Guillain-Barré showed an IgG increase, but of the 5 polyneuritis samples, 4 were within the control range (tab. 2).

Very oddly, although the viral origin of Guillain-Barré syndrome has never been clearly demonstrated, there were no significant differences when compared to a hyperimmune disease, such as subacute sclerosing panencephalitis.

In the group of demyelinating disease, the IgG range in amyotrophic lateral sclerosis was not markedly different from that of controls. In multiple sclerosis, although 
we considered a more important group than in a first paper (1), we were able to confirm our results (tab. 4).

In the group of the infectious disorders, the $k / \lambda$ ratios differed significantly from the controls only for the neurosyphilis group (tab. 4). However, in this group, only the active cases of neurosyphilis showed an increased $\kappa / \lambda$ ratio, whereas the remaining asymptomatic cases were entirely within the normal range. These results are somewhat different from earlier findings (7).

The $\kappa / \lambda$ values of highly infectious diseases such as meningitis, viral encephalitis and subacute sclerosing panencephalitis did not differ significantly from controls, al though agar gel electrophoresis frequently reveals oligoclonal IgG in the cerebrospinal fluid in these diseases.

Also, the range of individual values in these diseases are much more diversified than those of controls. For instance, in subacute sclerosing panencephalitis, we found values as high as $k / \lambda=6(1)$, and in viral encephalitis and meningitis values as low as 1.0 and 0.9 (tab. 2 and 3), which correlates well with the oligoclonal IgG.

The mean $\kappa / \lambda$ values in the polyneuropathy group are entirely within the control range, but 2 individual polyneuritis cases showed an increased $k / \lambda$ ratio, 2 cases of Guillain-Barré syndrome also showed increased $\kappa / \lambda$ values, and 2 other cases of Guillain-Barré syndrome showed decreased $k / \lambda$ values (tab. 2).

The $\kappa / \lambda$ values in amyotrophic lateral sclerosis and multiple sclerosis were both significantly different from mean controls, although not to the same extent; in an earlier paper (1) we were not able to detect these significant differences in multiple sclerosis cerebrospinal fluid, owing to the smaller number of patients under investigation.

The next 4 parameters, frequency of free light chains, of the double ring precipitation phenomenon, and of fractionated IgG in agar gel electrophoresis will be discussed together.

From table 4, it can be seen that the frequency of appearance of these 4 parameters increases steadily as a function of the degree of severity, of chronicity and the state of hyperimmunisation of the infectious diseases. Indeed the frequency is highest in subacute sclerosing panencephalitis and neurosyphilis, diseases which can evolve over very long periods in the order of years. Moreover, as mentioned above, hyperimmunisation against measles virus has been proven in subacute sclerosing panencephalitis.

For all groups under investigation, the highest frequency of free kappa chain, excluding subacute sclerosing panencephalitis, is seen in multiple sclerosis, and the double ring precipitation frequency is even higher than for subacute sclerosing panencephalitis. This is not so surprising, since multiple sclerosis evolves over periods which generally are much longer than in subacute sclerosing panencephalitis.

In the analysis of serum samples we were not able to consider the same number of diseases or samples as we did in the analysis of cerebrospinal fluid. However, in the analysed sera, the IgG and $\kappa / \lambda$ pattern and the frequency of double ring precipitation and fractionated IgG in agar gel electrophoresis were largely different from those found in cerebrospinal fluid (tab. 7).

In the group of infectious diseases, the mean serum IgG values differed significantly from the mean controls, only in subacute sclerosing panencephalitis. As viral encephalitis values were widely spread (tab. 6), the mean and control values were approximately the same.

Serum IgG in polyneuropathy was within the range of Link's observations (13), and the levels of IgG in amyotrophic lateral sclerosis and multiple sclerosis were en tirely normal.

Finally, the serum IgG in subacute sclerosing panencephalitis also differed significantly from that in the remaining pathological cases.

Conversely, serum $\kappa / \lambda$ ratios in the range of mean controls were only found in mean subacute sclerosing panencephalitis (tab. 7). The serum $\kappa / \lambda$ values were decreased in viral encephalitis, polyneuropathy and amyotrophic lateral sclerosis, but they were increased in multiple sclerosis.

There was a striking contrast between the serum $\kappa / \lambda$ values in amyotrophic lateral sclerosis and multiple sclerosis, although their IgG values were much the same.

Double ring precipitation frequency was negative for all cases under investigation; the frequency of fractionated IgG in agar gel electrophoresis was very high in subacute sclerosing panencephalitis, this being an already wellknown observation (10). Apart from a few viral encephalitis cases, all the other pathological samples showed no fractionation (tab. 7).

Consideration of matched cases of cerebrospinal fluid and serum from Guillain-Barré syndrome (tab. 2; cases 6,8 and tab. 6; cases 1,2) and polyneuritis (tab. 2; cases 4,5 and tab. 6; cases 3,4 ) shows that changes in IgG values and $k / \lambda$ in cerebrospinal fluid were not necessarely related to changes in serum.

In 4 matched samples of viral encephalitis, one case (tab. 3; case 3 and tab. 6; case 4) showed the same $\kappa / \lambda$ for serum and cerebrospinal fluid, while another case showed a similar IgG increase and the same $k / \lambda$ values in both body fluids (tab. 3; case 9 and tab. 6; case 7). 
In subacute sclerosing panencephalitis a parallel IgG increase was observed in serum and cerebrospinal fluid, but the $\kappa / \lambda$ values were considerably diversified.

Taking all these facts into consideration, we can draw the following conclusions for the neurological diseases we investigated.

1. In previous papers $(1,2)$ we investigated the double ring precipitation phenomenon in cerebrospinal fluid from multiple sclerosis and subacute sclerosing panencephalitis, and discussed the possible origin of this phenomenon; we advanced the hypothesis that immunoglobulins which carry light chains with incomplete antigenic determinants and which are specific for the disease, are synthesized in these particular diseases. We can now extend this concept, albeit to a less degree than in multiple sclerosis and subacute sclerosing panencephalitis, to viral encephalitis, meningitis, neurosyphilis and Guillain-Barré syndrome. The fact that the double ring precipitation phenomenon is not seen in the serum of these diseases and that there is a lack of correlation between matched cerebrospinal fluid and serum samples could perhaps suggest that the specific immunoglobulins are synthesized in the cerebrospinal fluid or the brain by a few committed lymphocytes.

2. Another possible explanation for the double ring precipitation is Lietze's hypothesis (14) i. e. blocking of antigenic determinants by other bound proteins, for instance immune complexes. In subacute sclerosing panencephalitis and multiple sclerosis, diseases which both display a high frequency of double rir. precipitation, immune complexes have been identi, in the cerebrospinal fluid and in the serum $(15,16)$.

In the Guillain-Barre syndrome, where the viral etiology has been suspected, but never clearly demonstrated, and where immune complexes have been observed $(16,17)$, double ring precipitation were noticed in several cases.

3. The presence of the free light chains in the cerebrospinal fluid in multiple sclerosis and subacute sclerosing panencephalitis was discussed elsewhere (2) and we stated that they could be due to a strong immunological stimulation. The fact that the frequency of the light chain increases as a function of the strength and duration of the immunological stimulus seems to confirm this assumption. There is a very positive correlation between the appearance of free light chains and the state of hyperimmunisation, or at least of strong immunisation. We think that the free light chains may be synthesized within the cerebrospinal fluid or the brain, being part of a defective immunoglobulin synthesis or of an overproduction of light chains.

In some individual cases of viral encephalitis, characterized by outstanding IgG values (tab. 3), either free $\kappa$ - or $\lambda$-chains were present in very large quantities (unpublished results). In subacute sclerosing panencephalitis, where measles antibody has been identified in the cerebrospinal fluid and brain, and where IgG is oligoclonal in almost every case, the free light chains reached the highest quantitative values of all the pathological cases under investigation (unpublished results).

\section{Conclusion}

1. In all the neurological diseases we considered, except amyotrophic lateral sclerosis, the immunological reactions are characterized by a general increase of the IgG in the cerebrospinal fluid, but not in serum.

Fractionation of the IgG is also much more frequent in cerebrospinal fluid than in serum of corresponding diseases; this particular feature is only largely confirmed in serum of subacute sclerosing panencephalitis patients.

Disturbed kappa-lambda light chain ratios are seen in cerebrospinal fluid from patients affected with amyotrophic lateral sclerosis, multiple sclerosis, neurosyphilis and subacute sclerosing panencephalitis, and in serum from amyotrophic lateral sclerosis, multiple sclerosis, polyneuropathy and viral encephalitis.

Changes in the IgG pattern in the neurological diseases we studied seem thus to be largely restricted to the cerebrospinal fluid, a fact which once more points to the possible synthesis of IgG within the nervous system. However, disturbed kappa-lambda ratios are also found in the serum as well as the cerebrospinal fluid, but not necessarily for the same category of disease.

The exception is multiple sclerosis, where, both in serum and cerebrospinal fluid, the mean ratios showed an increase of kappa. This particular feature, if thoroughly investigated on a large number of sera, could become important for the diagnosis of multiple sclerosis, and would suggest that in multiple sclerosis oligoclonal IgG is present in the serum, as in subacute sclerosing panencephalitis. One could assume that a few clones, possibly present, are not yet sufficiently predominant in the heterogenous background IgG, and consequently could not be demonstrated by procedures such as agar gel electrophoresis.

2. In a previous paper (1) we stated that particular immunoglobulins are possibly synthesized in the cerebrospinal fluid: predominantly kappa immunoglobulins for multiple sclerosis and lambda immunoglobulins for subacute sclerosing panencephalitis. As we progressed from 9 to 48 cases of multiple sclerosis, this impression was confirmed, since-the 
kappa-increase of the light chain ratios was conserved.

Moreover, in multiple sclerosis, the frequency of free kappa light chains was higher than that of the lambda light chains.

3. Free light chains are an index of either hyperimmunisation, or strong immunological processes in the central nervous system, since their frequency was highest in subacute sclerosing panencephalitis, neurosyphilis and viral encephalitis.

This again, draws attention to a possible synthesis of either light chains or immunoglobulins within the central nervous system.

4. The double ring precipitation phenomenon is a feature which is especially significant in multiple sclerosis and subacute sclerosing panecephalitis and seems to depend on the duration of the pathological processes, since they are most intensely pictured in those diseases.
In infections such as viral encephalitis and meningitis, which in general do not have the long evolution periods (i. e. years) that are found in multiple sclerosis and subacute sclerosing panencephalitis, the aspect of the double ring precipitation is not so clearcut or relevant. This is possibly because clones, committed to the synthesis of immunoglobulins specific for the disease, become more prevalent with time.

5. As a diagnostic tool, when screening neurological diseases, agar gel electrophoresis of the cerebrospinal fluid remains the indispensable parameter.

In order to distinguish multiple sclerosis, subacute sclerosing panencephalitis, or encephalitis from each other in atypical cases, the double ring precipitation and the kappa-lambda ratios should be investigated.

Finally, to evaluate the severity of inflammation in the central nervous system, free light chains should be studied.

\section{References}

1. Bollengier, F., Lowenthal, A. \& Henrotin, W. (1975), Z. Klin. Chem. Klin. Biochem. 13, 305-310.

2. Bollengier, F., Delmotte, P. \& Lowenthal, A. (1976), J. Neurol. 212,151-158.

3. Iwashita, H., Grunwald, F. \& Bauer, H. (1974), J. Neurol. $207,45-52$.

4. Wieme, R. J. (1965), Agar gel electrophoresis, Elsevier Publishing Company.

5. Mancini, G. A., Carbonarạ, A. \& Heremanns, J. (1965), Immunochemistry 2, 235-254.

6. Berggård, I. \& Edelman, G. M. (1963), Biochemistry 49, 330-337.

7. Link, H. \& Muller, R. (1971), Arch. Neurol. 25, 326-344.

8. Vandvik, B. (1973), Ann. Clin. Res. 5, 308-315.

9. Vandvik, B. \& Norrby, E. (1973), Proc. Nat. Acad. Sci. 70, 1060-1063.
10. Lowenthal, A. (1964), Agar gel electrophoresis in Neurology, Elsevier Publishing Company.

1. Van Welsum, R. A. \& van der Helm, H. J. (1970), Neurology 20,996-1001.

12. Rappel, M., Dubois-Dalcq, M., Sprecher, S., Thiry, L., Lowenthal, A., Pelc, S. \& Thys, J. P. (1971), J. Neurol. Sci. 12, 443-458;

13. Link, H. (1973), J. Neurol. Sci. 18, 11-23.

14. Lietze, A., Colin, S. \& Nowe, H. A. (1970), Clin. Biochem. $3,335-338$.

15. Oldstone, M. B. A., Bokisch, V. A. \& Dixon, J. F. (1975), Clin. Immunol. Immunopathol. 4, 52-58.

16. Tachovsky, T. G., Lisak, R. P., Koprowski, H., Theofilopoulos, A. N. \& Dixon, F. F. (1976), Lancet, II, 997-999.

17. Behan, P. O., Stilmant, M., Lowenstein, L. M. \& Sax, D. (1973), Lancet $I, 850-854$.
Dr. F. Bollengier

Laboratorium Fysiopathologie van het Zenuwstelsel

Vrije Universiteit Brussel

Everstraat 2

B-1000 Brussels, Belgium 
.

。 